\title{
Hunt the shadow not the substance: the rise of the career academic in construction education
}

\author{
Stuart Tennant ${ }^{a}$, Mike Murray ${ }^{b}$, Alan Forster ${ }^{c}$ \& Nick Pilcher ${ }^{d}$ \\ a School of Engineering and Computing, University of the West of \\ Scotland, Paisley PA1 2BE, UK \\ ${ }^{\mathrm{b}}$ Department of Civil \& Environmental Engineering, University of \\ Strathclyde, Glasgow G4 ONG, UK \\ ${ }^{\mathrm{c}}$ School of Energy, Geoscience, Infrastructure and Society, Heriot- \\ Watt University, Edinburgh EH14 4AS, UK \\ d School of Marketing, Tourism and Languages, Edinburgh Napier \\ University, Edinburgh, UK, EH14 1DJ
}

Teaching in Higher Education, DOI: 10.1080/13562517.2015.1070342

Published online: 12 Aug 2015.

\begin{abstract}
Construction education is context-laden, navigating and reflecting the byzantine influences of period, place and person. Despite considerable rhetoric, in UK higher education and construction studies in particular the importance of contextualized teaching is being devalued. Over the past decade a growing number of new teaching staff to university lecturing has limited or no industrial experience of the construction sector. This paper explores the rise of the career academic in construction education and implications for teaching standards and student learning. Whilst career academics exhibit research skills and afford funding possibilities that universities find appealing, pedagogical studies suggest that experience-led, contextualized teaching offer students enhanced educational value. Policy-making and pedagogical strategies that continue to value research at the expense of teaching excellence coupled with recruitment of career academics as opposed to industry professionals present new challenges for construction education, teaching and student learning.
\end{abstract}

Keywords: teaching; research; career academic; construction education 


\section{INTRODUCTION}

Given the title of the paper, an explanation of the phrase 'hunt the shadow not the substance' may be deemed appropriate. The term which has its origins in construction tutelage is attributed to Vitruvius (see Bowyer, 1993), famous for his first century treatise 'Ten Books of Architecture'. Roman engineer, architect and writer Vitruvius (Bowyer, 1993 p.223) asserted that:

"the architect ('Builder in Chief') should be equipped with knowledge and understanding of many different branches of learning, because they are required to judge the quality of artistic work. Architects ('Builder in Chief') who have manual skills and dexterity without scholarship are not able to reach the professional heights which their profession would warrant while those with scholarship and no practical skill hunt the shadow not the substance. Those who have a thorough knowledge of both practice and theory are in a position to obtain and wield authority."

To 'hunt the shadow not the substance' is thus to comprehend the fundamental principles governing technology and science whilst remaining detrimentally disconnected from the complex, diverse and often unique context of its useful and meaningful application. According to Vitruvius, true mastery of construction can only be acquired by exhibiting a 'thorough knowledge of both practice and theory'. Despite its ancient origins, the sentiment remains highly relevant for contemporary construction education (Bowyer, 1993).

Construction education is context-laden, navigating and reflecting the byzantine influences of period, place and person. The tradition of the master craftsman ascending to complete construction project oversight was the accepted educational route until 
relatively recent times (Snell, 1996). This system of neophytes learning through a rigorous, experiential process of apprenticeship and journeyman has enabled continuity of construction skills and behaviours that are practically important but also culturally significant. Over the past fifty years, the transformative nature of the university sector in the UK has provided a catalyst for ever-increasing interest in construction science and built environment studies. Whilst the educational backdrop, direction and experiential learning of the time-honoured 'master-builder' have unquestionably evolved, the custom of HE academics drawing upon the venerated vocational rationale of construction education has endured.

Recent developments in contemporary HE have begun to undermine the time-honoured relationship between construction theory and industry practice (Barr, 2008). In response to growing pressure to secure finite resources (Coate et al., 2001) in an increasingly crowded and highly competitive university sector, the prerequisite skill-set for a ‘modern-day’ construction academic has altered significantly (Peel, 2006). In stark contrast to previous employment criteria, prospective construction academics are routinely required to possess a Doctorate qualification as standard and demonstrate promising research capital. Indeed, one anonymous academic (The Guardian, 2014) argued that most engineering faculties are "for the most part, staffed by scientists and graduates with no industrial experience."

In a marked number of Built Environment departments across the UK, the professional practice and industry experience of that old-fashioned sort is no longer revered because it garners neither block funding nor assists with research portfolios (Collins and Davies, 2009). Inadvertently or otherwise, the coordinated and systematic pursuit for research excellence within UK universities and their engineering faculties has fragmented the relationship between construction theory and industry practice. This weakening of the 
vocational rationale has served to legitimize the introduction of a new-found class of construction lecturer; namely, the 'career academic'.

The growing popularity of the career academic in construction education is not without implication or consequence for teaching standards and student learning. Nor is it necessarily unique to construction education. Commenting on the creeping dominance of academic research in US engineering education, Ferguson (1992 p.159) charts a similar trajectory asserting that within a relatively short time-frame,

"it would become painfully obvious that engineering faculties had become strong in research but were generally unfamiliar with engineering practice, particularly design. Nor did the teachers have the necessary industrial experience to introduce the students to many subtle, unstructured problems of designing, building, operating and maintaining structures and machines."

Despite this cautionary anecdote, construction education and by extension UK policymaking continues to sponsor the polarization of funding between teaching and research (Coate et al., 2001, Laing et al., 2011, Peel, 2006). Such bifurcation has been acknowledged as divisive (Barr, 2008, Macfarlane, 2011) and raises professional and pedagogical anxiety about potential shortcomings in maintaining and developing the vocational foundation for construction programmes. According to Webster (2006) these failings facilitate the emergence of broad engineering faculties delivering increasingly generic programmes and with it the incumbent risk of becoming disengaged from the context-laden requirements of construction education (see Table 1.). 
Insert Table 1: The rise of the career academic in higher education

\begin{tabular}{|c|c|}
\hline Source: & Quote: \\
\hline $\begin{array}{l}\text { (Horne, } 1983 \\
\text { p.310) }\end{array}$ & $\begin{array}{l}\text { "In professional schools such as engineering, it is also accepted } \\
\text { that involvement with some practice is at least desirable. While } \\
\text { probably too few engineering teachers are involved sufficiently } \\
\text { with practice, it is also possible for involvement to be excessive." }\end{array}$ \\
\hline $\begin{array}{l}\text { (Felder, } 1994 \\
\text { p.107) }\end{array}$ & $\begin{array}{l}\text { "Unfortunately, the number of us who have ever done any of these } \\
\text { things [practical engineering] is small and shrinking. Since we are } \\
\text { most comfortable teaching what we know best, we teach less } \\
\text { engineering practice and more of engineering science we know } \\
\text { from our own graduate study and research." }\end{array}$ \\
\hline (Barr, 2008 p.20) & $\begin{array}{l}\text { "In due course, civil engineering degrees will be taught in many } \\
\text { universities by a team of academics without much industrial } \\
\text { experience, which may not prove good for the profession." }\end{array}$ \\
\hline $\begin{array}{l}\text { (Collins and } \\
\text { Davies, } 2009 \\
\text { p.14) }\end{array}$ & $\begin{array}{l}\text { "This is significant because there is concern about the decreasing } \\
\text { number of engineering academics with industrial experience, } \\
\text { resulting from pressure to recruit staff on the basis of research } \\
\text { achievement." }\end{array}$ \\
\hline $\begin{array}{l}\text { (Arlett et al., } 2010 \\
\text { p.23) }\end{array}$ & $\begin{array}{l}\text { "The role of academic staff is critical to providing students with } \\
\text { experience-led degree programmes. However, in recent years the } \\
\text { number of academic staff with prior experience in industry has } \\
\text { been declining, particularly in research-led universities." }\end{array}$ \\
\hline $\begin{array}{l}\text { Royal Academy of } \\
\text { Engineering, } 2014 \\
\text { p. } 21\end{array}$ & $\begin{array}{l}\text { "HE appointments are often driven by a need to improve the } \\
\text { research profile of an institution and many academics are } \\
\text { recruited on their research track record. The result is that fewer } \\
\text { lecturers in UK universities will have significant industrial } \\
\text { experience." }\end{array}$ \\
\hline (Plank, 2011 p.15) & $\begin{array}{l}\text { "the emphasis on research outputs within universities has led to } \\
\text { reduced mobility of individuals from industry into academia and } \\
\text { vice versa." }\end{array}$ \\
\hline $\begin{array}{l}\text { (Clarke, } 2012 \\
\text { p.203) }\end{array}$ & $\begin{array}{l}\text { "By 2010, most of these staff [academics recruited from industry] } \\
\text { had either left or were leaving university. They were, in general, } \\
\text { replaced by academics with little or no practical experience." }\end{array}$ \\
\hline $\begin{array}{l}\text { (Alplay and Jones, } \\
2012 \text { p.615) }\end{array}$ & $\begin{array}{l}\text { "Industrial experience and practical skills; a lack of these two } \\
\text { important characteristics is seen as faculty shortcomings, with } \\
\text { much variation in teaching skills and student understanding at the } \\
\text { point of appointment." }\end{array}$ \\
\hline $\begin{array}{l}\text { (Graham, } 2012 \\
\text { p.16) }\end{array}$ & $\begin{array}{l}\text { "An additional consequence of this increased pressure on } \\
\text { research output appears to have been the reduction in the number } \\
\text { of faculty with "real industry experience". }\end{array}$ \\
\hline $\begin{array}{l}\text { (Westacott, } 2013 \\
\text { p.17) }\end{array}$ & $\begin{array}{l}\text { "As a consequence, the chance of any relatively recent academic } \\
\text { appointment in chemical engineering having any significant } \\
\text { industrial experience is quite low." }\end{array}$ \\
\hline
\end{tabular}


Despite growing disquiet within industry and academia, many construction faculties continue to be steadfastly motivated by research objectives. An important driver for this focus has been the introduction and subsequent refinement of the Research Assessment Exercise (RAE) and Research Excellence Framework (REF) respectively. To achieve higher scores and receive research funding, lecturing staff are required to be research active. The results of the research audit feature prominently in national and global university league tables (Land and Gordon, 2015). The growing significance and financial benefits associated with the research audit (RAE \& REF) coupled with national and international league table position have had a notable impact on university recruitment strategy. Nowadays, for universities keen to compete in a crowded, competitive and increasingly global knowledge economy, construction industry exposure and professional experience now "counts for little when measured against four good journal papers" (Barr, 2008 p.20). In response to this increasingly worldwide consumerist approach to HE (Land and Gordon, 2015), remaining research passive as opposed to research proactive is no longer a sustainable proposition for the majority of construction faculties.

In UK HE, the relationship between teaching and research is complex, diverse and highly contested (Peel, 2006). Making sense of the growing popularity of the career academic in construction education and implications for future teaching and student learning requires contextual sympathy and sensitivity towards historical and cultural practices. Contextual awareness is not confined to the history of construction education. The evolving structural framework of HE also plays a prominent role. The transition from elitist institute to 'massification' and incumbent neoliberal philosophy (Snell, 1996, Jarvis, 2014) brought consequences that necessitated recalibration of professional identities (Beck and Young, 2005). 
Policy development over the past fifty years has reformed HE interpretation of the teaching-research nexus (Deem and Lucas, 2007, Stappenbelt, 2013). However, these developments must also be understood from competing perspectives (Peel, 2006). For different academic disciplines there are arguably discrete educational strategies, instrumentally bound by context, content and culture. For example, the notion of a research active, career academic delivering non-vocational programme(s) might be familiar within Arts or Humanities. Both exhibit a well-established standing as an academic endeavour. Yet, for many vocational subjects such as construction with its educational heritage in pupillage and guild structures (Koskela, 2000), the endorsement of career academics and research-led teaching at the expense of experience-led teaching is arguably felt more acutely. Incremental shifts in HE policy and the recalibration of professional identities jeopardize the long-standing logic that binds scientific principles with the grounded realities of construction practice and every-day problem solving. The fragmentation of theory and practice has been a recurrent theme throughout the twentieth century (Snell, 1996) and continues to generate considerable debate (Land and Gordon, 2015, Graham, 2015, Dempster et al., 2015). This is thus a polemic paper charting the rise of the career academic in construction education and exploring the implications for, and impact on teaching and student learning. The opening section of the paper traces three key policy developments in the provision of HE in the UK. The following section introduces the concept of the career academic and their ubiquitous appeal. The discussion section critically evaluates the rise of the career academic in construction education and considers implications and potential impacts on teaching standards and student learning. The paper concludes with reflections on the contribution of career academics in construction education and the urgent requirement for reimagined, revitalized and innovative experience-led teaching strategies. 


\section{CONTEMPORARY HIGHER EDUCATION IN THE UK}

To make sense of construction education within the HE sector, key policy events need to be reviewed. The past five decades has borne witness to a "period of kaleidoscopic growth and transformation" (Lowe, 2012 p.107) of the UK university system. The provision of $\mathrm{HE}$ has changed from an arguably elitist institution to a mass education system with "big business" (Coate et al., 2001 p.158) objectives. The rise of the career academic in construction education is arguably reflective of successive policy change and the incumbent consumerism that accompany an "evaluative and regulatory", (Jarvis, 2014p.156) form of accountability within a highly competitive and crowded marketplace.

Reasons for this transformation are complex (Wyness, 2010), contextual (Taylor, 2008) and profoundly significant for construction education. Three policy developments are noteworthy for their impact on the changing character of the UK HE sector and subsequent influence on the provision and delivery of construction education. Firstly, the Robbins Report published in 1963, secondly, The Further and Higher Education Act 1992 and finally, The Dearing Report published in 1997.

The Robbins Report (1963) was arguably the catalyst for ongoing reform in UK HE provision. This review of HE introduced an agenda for change, both in terms of increasing student accessibility and equality, and also revised conditions of engagement and accountability between HE and Central Government. Subsequent growth in student numbers was accommodated by the increase in UK universities. In 1960-61, universities in the UK numbered 33, over the next ten years (1960-61 to 1970-71) the number of UK universities grew to 44. Significantly, many of the newer post 1963 universities, colloquially know as 'plate-glass' universities had their scholarly origins in 
'Colleges of Advanced Technology' (Wyness, 2010) and the provision of predominately vocational programmes.

Further expansion was ratified in 1992 when enactment of The Further and Higher Education Act 1992 removed the 'binary line' between existing universities and polytechnics in England and Wales (Jarvis, 2014) and their counterparts in Scotland (universities and central institutes (CI)) (McNay, 2006). This policy development helped polytechnics and CI's rebrand as self-governing, post-1992 universities complete with newfound institutional power to award their own degrees. For many, this heralded the beginning of the present-day mass HE system (Scott, 1995).

The realignment of Further Education (FE) and HE boundaries was profound. Not only were FE students reclassified as HE, existing FE staff members immediately became 'part and parcel' of a revamped UK university system. Post-1992 universities with their pedagogical roots in the delivery of vocational programmes now had to compete with highly respected (Ancient \& Red Brick) universities and the more recent post-1963 (Plate-Glass) universities.

In response to the considerable challenges this presented, the Dearing Report (1997) set out progressive proposals aimed to deliver affordable, accountable and sustainable mass HE. Key recommendations (Dearing, 1997) included the introduction of upfront student tuition fees alongside near universal access to low interest student loans. To oversee the revised HE structure, a new regulatory agency was established; namely, The Higher Education Quality Council (HEQC) (Jarvis, 2014). Whilst the guiding principles outlined in Dearing (1997) disclose many parallels with previous consultations (see Robbins, 1963); for the first time, the economic rationality between $\mathrm{HE}$ and wealth creation was made explicit. 
In the UK, HE is now "big business" (Coate et al, 2001 p.158) and forms an integral part of the "enterprise culture" and the incumbent "market-dominated beliefs" it promotes (Snell, 1996 p.320). Given students would now be 'investing' metaphorically and literally in their HE learning experience; the economic 'value' of a university degree swiftly attained a more pertinent and private role. Drawing upon comparison with the elitist institutional frameworks of yesteryear, post-1963 and post-1992 universities with their extended history in delivering vocational programmes now play an important and potentially lucrative part in "a very complex knowledge producing game" (Gibbons et al., 1994 p.65). Central to institutional success is the securing of teaching and research funding and the restructuring of academic and professional identities (Beck and Young, 2005).

\section{Funding}

Options for university funding remain diverse; however there are essentially two funding streams; 1 / allocated funding based on student access, enrolment and progression and 2/ allocated funding based on an external audit of research excellence. The former is largely based on student tuition fees (although an alternative centrally funded model exists in Scotland). The latter is more complex but revolves around the periodic RAE or more recently, the REF 2014.

Given the critical role of finance to institutional well-being, access to funding dominates university policy-making. This has arguably created a 'principled' pedagogical tension between two discrete teaching strategies namely, experience-led or an alternatively research-led framework (Stappenbelt, 2013). Whereas experience-led teaching places knowledge, understanding and contextual learning at the heart of programme delivery, research-led strategies shift the educational focus, promoting knowledge and understanding supported by research (theory). 
Whilst it is acknowledged that teaching strategies vary from university to university, Land and Gordon (2015) suggest that the acute disparity between teaching and research funding is likely to have a marked effect on academic judgment and educational outcomes. In response to pedagogical bifurcation (Macfarlane, 2011), funding disparity and ongoing commercialization of the HE system (Coate et al., 2001, Beck and Young, 2005), the professional identity of university academics is being redefined (Nixon et al., 2001, Locke, 2014).

\section{The New Academic}

The restructuring of academic and professional identities in HE has been widely acknowledged. According to Peel (2006 p.43), this transformation has engendered a "new academic". The new academic is not disconnected from the more 'mature' academic in terms of workload, ambition or workplace anxiety. They both inhabit the same work environment; however the new academic's interpretation of mass HE and their subsequent management of teaching and research responsibilities arguably set them apart.

For the new academic, university teaching duties have become routinely varied and increasingly administrative. A discerning student population now seek university courses that explicitly complement employment supply and demand. This requires faculty members to regularly collate a profusion of engagement statistics, co-ordinate accreditation visits and promote educational programmes addressing the interests of a dynamic and increasingly specialized graduate marketplace.

In addition to ever-expanding teaching duties, the 'new' academic also has dual research commitments. According to Nixon (1996 p.7) "the changing conditions of academic work have placed a premium on the professional identity of the university 
teacher (lecturer) as a researcher, capable of attracting external funding within an increasingly competitive research culture". The periodic research excellence audits, first introduced in 1986 (Peel, 2006), have been a powerful determinant in shaping university funding strategies and re-orientating academic roles.

In essence, the 'new academic' identified by Peel (2006) is characteristic of successive HE policy-making that endorses bifurcation of teaching and research (Taylor, 2008). To satisfy the dichotomy of teaching and research, career mobility for the new academic is increasingly governed by educational qualifications ( $\mathrm{PhD}$ 's), research outputs and 'REF' returnable status. In many engineering faculties competing for potentially very significant sums of money (Coate et al., 2001) driven by periodic research audits, external reputation and league tables, a new-found class of lecturer has grown in popularity; namely, the construction 'career academic'.

\section{THE CAREER ACADEMIC IN CONSTRUCTION EDUCATION}

The notion of a career academic may have a slightly more established presence in Arts and Humanities, where the locus of pedagogical enquiry and knowledge sharing is embedded in expressions of human understanding and experience and remains largely disengaged from any detailed vocational rationale (Ferguson, 1992). In stark contrast, construction education is rooted in expressions of vocational learning and workplace experience and is context-laden. The concept and subsequent growing popularity of a career academic delivering construction studies is therefore a relatively recent phenomenon.

Whilst the term is without formal recognition, a career academic may be characterized as a research active university staff member with very limited professional or practical experience of working in the industry in which they are a scholar. The career academic 
typically left school (fifth / sixth year) to enrol at university; after successfully completing their first / second degree, the new post-graduate would continue studying at university and undertake a doctorate $(\mathrm{PhD})$. Upon completion, they would continue to work at university as a research assistant / associate (RA). After completing a number of research tenures, the prospective career academic would seek full-time employment at university as a research active lecturer (Barr, 2008) where their academic capital would be measured in grant funding and research outputs. Thus, the learning, employment and experience of the construction career academic is firmly embedded in a university work-life environment.

Despite growing disquiet amongst industry and academia, recent evidence suggests many vocational disciplines within UK universities are prioritizing the recruitment of career academics (Collins and Davies, 2009, Arlett et al., 2010, Lamb et al., 2010, Clarke, 2012, Graham, 2012). According to Barr (2008 p.20) this distorted staffing policy has created a perverse situation where industry experience is largely inconsequential when measured against research capital. Whilst career academics exhibit research skills and afford funding possibilities that universities find appealing, the implications for teaching standards and student learning in construction education are rarely explored.

\section{DISCUSSION: CONSTRUCTION EDUCATION AND SOME IMPLICATIONS FOR TEACHING AND STUDENT LEARNING}

This paper's key argument is that the recruitment of career academics has been and will continue to be detrimental to the quality of construction education and the student learning experience (see Table 1.). Yet to date, there has been limited debate in the development of coherent and industry relevant strategies (teaching and/or 
organizational) specifically designed to counter this markedly changing academic demographic.

The concern is not solely teaching quality per se, but also the inability to provide a contextual learning experience. Whilst career academics undoubtedly add value to wider research and institutional goals, they can be severely inhibited when construction students seek clarification and reassurance regarding the industrial validity of their university learning. Unless these latent shortcomings are acknowledged and mitigated, expected standards and industry confidence in construction education is likely to be compromised. Without thorough knowledge of both practice and theory as advocated by Vitruvius (see Bowyer, 1993), there is a risk that career academics in construction education present the image of a 'disengaged' role model.

Potential detractors might assert that university studies should not be specifically tailored to deliver a context-laden and professionally orientated syllabus. Searching for justification, some may be tempted to draw a conceptual distinction between education and training (Williams, 2005). It has previously been suggested that the role of a university academic is to educate those who wish to pursue a career in construction, rather than train students in specific technical practices (Severn, 1991).

Seeking solace in such a stance however, would fall foul of engineering education philosophy. The Engineering Council (2014 p.3) clearly state "all students deserve an engineering education that is world-class and that develops industry-relevant skills". It remains a paradox of contemporary construction education that undergraduates who secure industrial work placement during their studies will in all likelihood accumulate more industry relevant experience than many of their career academic tutors. 
Accepting that 'industry relevant skills' remain pivotal, teaching strategies need to be urgently re-imagined to counter the potential experiential and contextual limitations of a restrictive, context-light recruitment policy. Three distinct educational strategies arguably dominate the debate: first; academic secondment to the construction industry, second; university and industry partnerships and third; organizational culture. Individually and collectively these strategies provide a credible response to the imminent challenges facing teaching standards in construction education.

\section{Construction Industry Secondment}

Encouraging short-term industrial secondment for university lecturing staff is not new. The Royal Academy of Engineering (Lamb et al., 2010) have for a number of years endorsed the idea of work placement for university academics. The objective is unambiguous; to provide university academics with an 'industrial' context to benefit and enrich their existing knowledge and teaching of engineering studies. Despite evidence pointing to the benefits of such initiatives (Westacott, 2013), it remains unclear how popular industry secondments have been. Anecdotal evidence suggests that industry secondment opportunities for construction academics remain negligible.

Given the growing number of career academics teaching construction studies, the apparent lack of strategic intent regarding workplace secondment needs to be confronted. Failure to offer a carefully structured industrial secondment programme stands contrary to the opportunities afforded career academics in developing and refining teaching and research skills. Career academics securing their first permanent lecturing post typically attend a teaching and learning induction course, addressing topics such as student learning and engagement, teaching methods, reflective practice and programme design (Land and Gordon, 2015). Thereafter and ordinarily within two 
years of full-time employment, new members of academic staff are required to undertake a Post Graduate certificate in Higher Education (PGcert HE).

Despite a career academics newfound status as 'educator' and 'construction' role model, what is not addressed in any substantive manner is the lack of industry exposure and workplace experience. In the past, this would not be a primary concern as prospective construction lecturers would typically take up lecturing posts mid-career, complete with professional and industrial experience (Deem and Lucas, 2007). Yet, unlike their predecessors, construction career academics require instruction in teaching competences and exposure to industry practice, both of which require management intervention.

Drawing on the secondment scheme outlined by the Royal Academy of Engineering, a mandatory three to six months industrial placement for construction career academics would be a credible starting point. Unfortunately in the present climate, seeking justification to circumvent industry secondment is likely to be tempting. Given the prevailing institutional culture that rewards research excellence, career academics may be reluctant to 'volunteer' for work placement or indeed "close themselves off from the whole enhancement discourse" (Dempster et al., 2015 p.43). A situation conceivably compounded by senior management reluctance to 'interrupt' the funding potential of research-active faculty members, despite evidence highlighting the educational benefits for both staff and students.

\section{Construction Industry Partnerships}

In addition to secondment opportunities, the contribution of construction industry practitioners in the delivery of HE studies needs to become a teaching priority (Williams, 2005, Graham, 2015). At present construction faculties are likely to have an 
established industrial advisory board (IAB). The concept of the IAB is well-meaning and creditable. Whilst there remain a paucity of empirical studies assessing their contribution, according to Barr (2008) over the past twenty years IAB's have failed to make the positive impact originally intended. There are numerous explanations for IAB panel members to perform largely as observers, including; unfamiliarity with the curriculum, little understanding of departmental resources (human and physical), and hesitancy to become embroiled in university politics.

Yet, without support from industry practitioners, construction faculties will increasingly struggle to offer excellence in education and learning. The already sensitive relationship between academia $\&$ industry and the continuing fragmentation of theory $\&$ practice is arguably compounded by the recruitment of career academics in construction education. Whilst construction faculties ought to invite IAB members to consider a more proactive role, any latent scepticism between academia and industry needs to be proactively managed by senior faculty members.

Explicit guidelines for industry engagement in subject delivery are required to provide confidence, assurance and clarity regarding perceived outcomes. This will necessitate strong leadership, institutional investment, greater collaboration and industry / teaching partnerships extending beyond the largely symbolic IAB arrangements currently in place. Initiatives may include; an integrated and structured programme of guest lectures', - complete with tutorial support and assessment input, carefully orchestrated construction site visits - including onsite classrooms, project documentation and handouts (Deem and Lucas, 2007), student mentoring programmes with structured work placement opportunities and sponsorship of industrial secondment opportunities for all staff members and especially career academics. 
Constructionarium is an enlightened albeit singular example of academia / industry engagement. Bringing together academics, design consultants and construction contractors, Constructionarium is a six day residential course whereby students get a 'hands-on', 'boots in the mud' learning experience involving the planning and construction of a scaled down version of an iconic structure. Started in 2003, Constructionarium was devised at the Imperial College, London in response to growing concerns that graduates were unable to apply theoretical principles in workplace situations (Chan, 2009, Alhearn et al., 2011). Whilst Constructionarium was conceived with student learning in mind, the benefits are not restricted to participating students. According to Alhearn et al (2005 p.7) it also keeps lecturing staff 'grounded' in the realities and every-day challenges of construction activity. However, for career academics devoid of significant industry exposure this is a very short sojourn as an observer. It could be strongly argued that construction faculties should form academic project teams to fully participate as learners as opposed to observers.

Despite faculties having well-meaning IAB, there remains a tendency for activities such as site visits, work placement and events like constructionarium to be organized in an ad-hoc fashion, by individual staff members, self-motivated and working independently. This 'good-will' arrangement for the delivery of contextual teaching and learning is untenable. Indeed, a report published by the Scottish HE enhancement committee (SHEEC) (Dempster et al., 2015 ) cites a growing research-teaching disconnect, with academic staff opting-out of teaching enhancement opportunities in order to pursue potentially lucrative research profiles.

With few exceptions, it is evident that existing HE / construction industry arrangements are outmoded and require a modern framework for world-class education "that develops industry-relevant skill," (Engineering Council, 2014, p.3). Construction education 
devoid of contextual teaching is unlikely to meet the economic, societal, environmental and technological challenges of a modern and progressive industry. Given the ubiquitous appeal of career academics, it is imperative that construction professionals working in industry are encouraged to fully participate in a community of construction education and practice. The benefits of closer academia / industry relations are arguably threefold; (1) enhanced teaching of construction studies, (2) opportunities for knowledge transfer partnerships and (3) the fostering of research ideas.

\section{Organizational Culture}

According to (Graham, 2015 p.1), "building a career in any subject means balancing the demands of teaching with research opportunities," however for academics that focus on teaching excellence "there is a question of whether they are provided with the same opportunities for career progression as their research-focused colleagues." A "strategic attempt to effect change in the prevailing predominant research culture" of HE has been the stratification of research and teaching staff (Land and Gordon, 2015 p.18). Lecturers with industry experience, it has been argued, have a propensity to concentrate on and be committed to teaching (Alplay and Jones, 2012) whereas career academics contribute to the creation and maintenance of a research orientation (Fairweather and Paulson, 1996). This correlation is consistent with recent findings (Graham, 2015 p.14) which suggest teaching specialists "may be better placed to contextualize student learning in authentic 'real world' engineering”. Despite well-intended motives, the prevailing culture routinely identifies research active staff and their non-teaching activities as an institutional priority (Macfarlane, 2011, Graham, 2015).

Given this bias (perceived or otherwise), the reputation of teaching excellence in HE continues to be devalued (Macfarlane, 2011). Graham's (2012) research on behalf of the Royal Academy of Engineering (RAE), concluded that the dominant culture in 
engineering departments is routinely characterised by prioritising research; a strategy which is reflected in the appointment and promotion process ( $c f$. Cashmore et al., (2013). The report concluded that the research and funding culture embedded in many universities remains a major barrier to effective reward and recognition of teaching. This situation is compounded by the periodic REF (Dempster et al., 2015). Despite rhetorical evidence of teaching-based career trajectories, institutional acceptance and parity with research pathways would appear to remain largely unproven and uncommon.

In an effort to mitigate emergent career tensions between construction teaching and research objectives, two broad pathways for faculty career advancement are beginning to emerge (Felder, 1994, Cashmore et al., 2013), namely; a research pathway (research fellow) and a teaching pathway (teaching fellow). A research pathway accommodates the career academic employment profile, where emphasis is placed on research performance. Following this pathway, the academic capital of the staff member is measured in external funding, commercial activities, research publication(s) and 'REF' returnable status. Research activity is supplemented with a limited teaching portfolio. Conversely, the teaching pathway promotes excellence in pedagogical related studies. Emphasis is focused on teaching performance, programme development, academic scholarship and promoting the educational and learning experience of the student. Research undertaken by Cashmore et al (2013) noted that many UK universities have introduced career pathways that recognise and reward teaching and learning. However, the final report also demanded a robust criterion to measure excellence in teaching and learning to provide parity with research-active colleagues and the established REF criteria. This would help confront the dominant perception that teaching is careerlimiting whereas research activity is career-building (Dempster et al., 2015). 
Regrettably, any impetus to establish teaching fellow pathways that have equivalence with research-active career opportunities appears to have been hijacked. Contrary to the positive and well-intended encouragement from the Higher Education Academy (HEA), senior management within universities have arguably undermined the credibility of the teaching fellow status by skilfully crafting its implementation to achieve 'competitive advantage' in REF assessments (UCU, 2013, Graham, 2015). This 'big-business' interpretation and enactment of the teaching fellow pathway is indicative of a deep rooted research 'first' organizational culture. Given institutional policy-making remains resolutely research orientated, it remains questionable whether a sufficient level of transparency exists or is attainable to thwart a growing culture of anxiety and tension amongst designated construction teaching fellows and research-active career academics. To date, a staff development scheme originally intended to instil parity between teaching and research excellence has been built on 'shaky' foundations. Indeed, Locke (2014 p.28) concluded that the future prosperity of higher education will depend on ensuring the 'attractiveness of careers in academia' and called for a better understanding of how "we conceive, build and sustain the careers and work of those" employed in higher education. Further research is needed to complement dynamic academic career aspirations with the complex, diverse and highly contested requirements of contemporary higher education.

\section{CONCLUSION}

The rise of the career academic in construction education is emblematic of recent HE policy-making. No longer can it be taken for granted that construction academics exhibit the professional and 'first-hand' industry experience that distinguished their academic predecessors. The changing employment profile of construction academics is 
not devoid of consequence, however to suggest the current course of action is reversed is unrealistic.

Given their lack of construction industry practice, there remains a risk that stakeholders resistant to the commercialization of HE may perceive career academics in a disapproving light. This would be misguided. The issue is not simply a critique of the career academic and their personal engagement with construction education. To judge the performance of contemporary educational standards against old-fashioned ideals firmly rooted in the past is highly dubious. These time-honoured values along with the 'education for education's sake' perception of the university academic have been irreversibly eroded and subsequently displaced.

To lament the demise of traditional HE values is therefore counterproductive. The challenge for construction education is to acknowledge the dynamic demands of a global knowledge economy and adjust accordingly. Unfortunately, whilst the HE environment has undergone significant transformation, teaching methods, practices and engagement frameworks with construction industry stakeholders have remained largely unaltered.

There is an urgent requirement to re-imagine, revitalized and re-invigorate experienceled teaching strategies in construction education. Mandatory construction industry secondment, proactive IAB, contextual learning events, partnerships with industry collaborators and parity in research and teaching career trajectories will undoubtedly make a positive contribution to the quality and standard of construction teaching and research. Substantive change will be problematical and require uncommon leadership; that will be the responsibility of the UK Government as regulator, construction industry representatives as moderator, the HE sector as employer and academics as role models. 


\section{REFERENCES}

ALHEARN, A., POPO-OLA, S., CIRIBINI, A. \& GIRMSCHEID, G. 2011. A Cultural Divide? Different modes of teaching construction management. In: DRITSOS, S. (ed.) EUCEET. Patras, Greece: EUCEET.

ALHEARN, A., WISE, C., MCCANN, E. \& GORING, P. 2005. Constructionarium: building to learn. $C E B E, 2,6-16$.

ALPLAY, E. \& JONES, M. E. 2012. Engineering educationin research intensive universities. European Journal of Engineering Education, 37, 609 - 626.

ANONYMOUS. 2014. What do uni engineering departments need most? People in overalls. Guardian.

ARLETT, C., LAMB, F., DALES, R., WILLIS, L. \& HURDLE, E. 2010. Meeting the needs of industry: the drivers for change in engineering education. Engineering Education, 54, 18 - 25.

BARR, B. 2008. UK civil engineering education in the twenty-first century. Proceedings of the Institution of Civil Engineers - Management, Procurement and Law, 161, 17 - 23.

BECK, J. \& YOUNG, M. F. D. 2005. The assault on the professions and the restructuring of academics and professional identies: a Bernstein analysis. British Journal of Sociology of Education, 26, 183 - 197.

BOWYER, J. 1993. History of Building 2nd. Edition, Bristol, Attic Books.

CASHMORE, A., CANE, C. \& CANE, R. 2013. Rebalancing promotion in the HE sector: is teaching excellence being rewarded? York: Higher Education Academy. 
CHAN, P. W. 2009. The Dominance of Practice in Constructionarium: Exploring the challenges of linking theory and practice. In: DAINTY, A. R. J. (ed.) ARCOM. Nottingham, UK: ARCOM.

CLARKE, B. 2012. The 2011 James Forrest Lecture - engineering education - a historical perspective of the future. Civil Engineering and Environmental Systems, 29, $191-212$.

COATE, K., BARNETT, R. \& WILLIAMS, G. 2001. Relationships Between Teaching and Research in Higher Education in England. Higher Education Quarterly, 55, $158-174$.

COLLINS, K. \& DAVIES, J. 2009. Feedback through student essay competitions: what makes a good engineeering lecturer? Engineering Education, 4, 8 - 15.

DEARING, R. 1997. National Committee of Inquiry into Higher Education Report of the National Committee, the Dearing Report. Norwich: HMSO.

DEEM, R. \& LUCAS, L. 2007. Research and teaching cultures in two contrasting UK policy contexts: Academic life in Education Departments in five English and Scottish universities. Higher Education, 54.

DEMPSTER, S., SAUNDERS, M. \& DAGLISH, D. 2015. Evaluation of the Enhancement Themes 2014: final report. In: QAA (ed.). Glasgow: QAA Scotland.

ENGINEERING_COUNCIL 2014. The Accreditation of Higher Education Programmes. London: Engineering Council.

FAIRWEATHER, J. \& PAULSON, K. 1996. Industrial Experience: Its Role in Faculty Commitment to Teaching. Journal of Engineering Education, 85, 209 - 215. 
FELDER, R. M. 1994. The Myth of the Superhuman Professor. Journal of Engineering Education, 83, 105 - 110.

FERGUSON, E. S. 1992. Engineering and the Mind's Eye, London, The MIT Press.

GIBBONS, M., LIMOGES, C., NOWOTNY, H., SCHWARTZMAN, S., SCOTT, P. \& TROW, M. 1994. The New Production of Knowledge: The Dynamics of Science and Research in Contemporary Societies. London: SAGE Publications.

GRAHAM, R. 2012. Achieving excellence in engineering education: the ingredients of successful change. The Royal Academy of Engineering.

GRAHAM, R. 2015. Does teaching advance your academic career? Perspecties of promotion procedures in UK higher education. Royal Academy of Engineering.

HORNE, M. 1983. Academia - the role of the higher education establishments. The Structural Engineer, 61, 310 - 311.

JARVIS, D. S. L. 2014. Regulating higher education: Quality assurance and neo-liberal managerialism in higher education - A critical introduction. Policy and Society, $32,155-166$.

KOSKELA, L. 2000. An exploration towards a production theory and its application to construction. VTT Technical Research Centre of Finland.

LAING, R., BUDA, G., DEVANEY, S. \& ROBERTS, D. 2011. Built Environment Higher Education in Scotland: Pressures, Challenges and Change in Uncertain Times. CEBE Transactions, 8, 41 - 59.

LAMB, F., ARLETT, C., DALES, R., DITCHFILED, B. \& PARKIN, B. 2010. Engineering graduates for industry. The Royal Academy for Engineering. 
LAND, R. \& GORDON, G. 2015. Teaching exellence initiatives: modalities and operational factors. York: The Higher Education Department.

LOCKE, W. 2014. Shifting academic careers: implications for enhancing professionalism in teaching and support learning. York: The Higher Education Academy.

LOWE, R. 2012. The changing role of the academic journal: the coverage of higher eduation in History of education as a case study, 1972-2011. History of Education, 41, 103 - 115.

MACFARLANE, B. 2011. Prizes, pedagogic research and teaching professors: lowering the status of teaching and learning through bifurcation. Teaching in Higher Education, 16, 127 - 130.

MCNAY, I. 2006. Delivering Mass Higher Education - The Reality of Policy in Practice. In: MCNAY, I. (ed.) Beyond Mass Higher Education. Maidenhead: SRHE and Open University Press.

NIXON, J. 1996. Professional identity and the restructuring of higher education. Studies in Higher Education, 21, 5 - 16.

NIXON, J., MARKS, A., ROWLAND, S. \& WALKER, M. 2001. Towards a New Academic Professionalism: A manifesto of hope. British Journal of Sociology of Education, 22, 227 - 244.

PEEL, D. 2006. Planning Educational Research and the UK Research Assessment Exercise. Journal for Education in the Built Environment, 1, 30 - 50.

PLANK, R. 2011. Adding value: Structural engineering as a global profession. The Structural Engineer, 89, 12 - 17. 
ROBBINS, C. B. 1963. Report of the Committee Appointed by the Prime Minister under the Chairmanship of Lord Robbins. London: HMSO.

SCOTT, P. 1995. The Meanings of Mass Higher Education, Buckingham, SRHE and Open University Press.

SEVERN, R. T. 1991. Presidential Address 1990: Views from the Ivory Tower. ICE Proceedings, 90, 1 - 28.

SNELL, K. D. M. 1996. The apprenticeship system in British history: the fragmentation of a cultural institution. History of Education, 25, 303 - 321.

STAPPENBELT, B. 2013. The effectiveness of the teaching-research nexus in facilitating student learning. Engineering Education, 8, 111 - 121.

TAYLOR, J. 2008. The teaching-research nexus and the importance of context: a comparative study of England and Sweden. A Journal of Comparative and International Education, 38, 53 - 69.

UCU 2013. The Research Excellence Framework (REF) UCU Survey Report. UCU: University and College Union.

WEBSTER, C. 2006. Practice-bounded Knowledge. CEBE, 3, 1 - 8.

WESTACOTT, R. 2013. Education: Get Real. The Chemical Engineer, 36 - 37.

WILLIAMS, A. 2005. Industry Engagement in the Built Environment. CEBE, 2, 1 - 5.

WYNESS, G. 2010. Policy changes in UK higher edcuation funding, 1963-2009. In: SCIENCE, D. O. Q. S. (ed.). London: Institute of Education University of London. 